\title{
The Top 100 Most Cited Articles Published in Dentistry: 2020 Update
}

\author{
Faris Yahya Asiri ${ }^{1, *}$, Estie Kruger ${ }^{2}$ and Marc Tennant ${ }^{2}$ \\ 1 Department of Preventive Dentistry, College of Dentistry, King Faisal University, Al-Ahsa 31982, Saudi Arabia \\ 2 International Research Collaboration-Oral Health and Equity, School of Human Sciences, Faculty of Science, \\ The University of Western Australia, Perth, WA 6009, Australia; estie.kruger@uwa.edu.au (E.K.); \\ marc.tennant@uwa.edu.au (M.T.) \\ * Correspondence: fasiri@kfu.edu.sa; Tel.: +966-567-727779
}

Citation: Asiri, F.Y.; Kruger, E.; Tennant, M. The Top 100 Most Cited Articles Published in Dentistry: 2020 Update. Healthcare 2021, 9, 356. https://doi.org/10.3390/ healthcare 9030356

Academic Editor: Takahiro Kanno

Received: 30 January 2021

Accepted: 26 February 2021

Published: 21 March 2021

Publisher's Note: MDPI stays neutral with regard to jurisdictional claims in published maps and institutional affiliations.

Copyright: (c) 2021 by the authors. Licensee MDPI, Basel, Switzerland. This article is an open access article distributed under the terms and conditions of the Creative Commons Attribution (CC BY) license (https:// creativecommons.org/licenses/by/ $4.0 /)$.

\begin{abstract}
This bibliometric review is aimed to analyze the top 100 most-cited publications in dentistry and to compare its outcomes. A literature search was performed using Elsevier's Scopus, without any restriction of language, publication year, or study design. Of 336,381 articles, the top 100 were included based on their citation count, which ranged from 638 to 4728 citations (Feijoo et al., 326 to 2050). The most productive decade was the 2000s, with 40 articles on the list (Feijoo et al., 1980s: 26). Marx RE (7\%) was the major contributor in this study (Feijoo et al., Socransky SS: 9\%), and almost half $(48 \%)$ of articles were from the USA. Of the top 100 articles, $26 \%$ focused on periodontology (Feijoo et al., periodontology: $43 \%$ ), while $17 \%$ of the total were published in the Journal of Dental Research (Feijoo et al., Journal of Clinical Periodontology: 20\%). Most of the publications were narrative reviews/expert opinion (36\%), (Feijoo et al., case series: $22 \%$ ), and were within the evidence level V (64\%) (Feijoo et al., 54\%). The citation count that a paper secures is not necessarily a reflection of research's quality, however, the current analysis provides the latest citation trends in dentistry.
\end{abstract}

Keywords: bibliometric analysis; citation analysis; dentistry; most cited

\section{Introduction}

As a science, dentistry has reached a high maturity level in recent decades [1]. In academia, journals play a crucial role by disseminating technical and scholarly work, peerreview and evaluating research, archiving such research, and providing a foundation for scholarly credits [2]. In 2004, Olk and Griffith stated that journals serve as the primary source of knowledge in a particular specialty. They argued that the boundaries of a given discipline are pushed by scholars, however, journals are essential to advance the main body of knowledge [3]. The American Journal of Dental Science, the world's first dental journal, began its publication in 1839 [4]. Since then, journals in dentistry have been performing as a mode of communication and source of knowledge within the dental community and other related fields. Hence, valid and reliable tools are necessary to analyze and document several changes that may occur in the lifetime of a single academic journal or group of journals [2].

Citations are potential indicators of a publication's impact in this expanding scientific literary environment [5]. A citation is an alphanumeric expression that acknowledges a particular subject's contribution to others' research [6,7]. Citation analysis is a bibliometric method to identify articles with the greatest impact on research and the clinical community in a given discipline [8], providing the foundation for developing new research lines, techniques, and theories. This method has been adopted in different dentistry subfields including endodontics, orthodontics, periodontology, implant dentistry, prosthodontics, oral and maxillofacial surgery, dental traumatology, dental caries, oral squamous cell carcinoma, oral submucous fibrosis, oral leukoplakia, cleft lip and palate, and medicationrelated osteonecrosis of the jaw (MRONJ) [9-22]. The definition of "classic article" has been 
a controversial topic across disciplines, and the most commonly suggested criterion has been the securing of a certain citation count, for instance, at least 400 citations $[8,23,24]$. However, a publication having accomplished 100 or more citations can also be termed as a "classic publication," depending upon the field under consideration, such as dentistry [25].

This bibliometric review aimed to identify and analyze the scientific activity of dental sciences up to 2020. The Elsevier's Scopus database was utilized to accomplish three specific objectives: (a) characterize the dental research in association with output, impact, geographic origin, authorship, topic, methodology design, and evidence level; (b) thematically categorizing research in dental areas, analyzing their interactions and evaluating their up-to-date trends; (c) assess any changes in citation trends of dentistry articles when compared with a similar, but much earlier study, published by Feijoo et al. [9] in 2014.

\section{Results}

\subsection{Citation Count, Citation Density, and Current Citation Index}

The primary characteristics of the top 100 most-cited articles in dentistry are shown in Supplementary Table S1. Overall, the 100 most-cited articles published in dentistry journals achieved a total of 113,482 (Scopus) and 214,642 (Google Scholar) citations; with the citation count varying between 638 and 4728 (Scopus), and 138 and 8281 (Google Scholar). According to Scopus, 33 articles exceeded 1000 citations; with 33 articles securing more than 2000 citations as per Google Scholar. The most cited article, with a total of 4728 (Scopus), 8281 (Google Scholar) citations, was as a clinical trial titled "Periodontal Disease in Pregnancy II. Correlation between Oral Hygiene and Periodontal Condition" [26], and was published in the Acta Odontologica Scandinavica. Its citation density was 84, with the current citation index of 269. The second most cited article, with a total of 4062 (Scopus), 7873 (Google Scholar) citations, was similar to the first article, but was published one year earlier titled "Periodontal disease in pregnancy I. Prevalence and severity" [27], and was also published in the Acta Odontologica Scandinavica. Its citation density was 71, with the current citation index of 232. The third most cited article, with a total of 3392 (Scopus), 6257 (Google Scholar) citations, was also a clinical trial titled "A 15-year study of osseointegrated implants in the treatment of the edentulous jaw" [28] and was published in the International Journal of Oral and Maxillofacial Surgery. Its citation density was 117, with the current citation index of 96.

As per citation density, a review by Guo and DiPietro [29] has the highest score, i.e., 186. In the second rank, with a citation density of 181, is an article related to the category of classification or tools for assessing results [30]. The third-ranked article (citation density of 167) is a position paper by Ruggiero et al. [31]. According to the current citation index 2020, the top-ranked article was a review published in 2010, securing 345 citations [29]. The second-ranked article was a recommendation paper related to the category of classification or tools for assessing results written by Schiffman et al. [30] in 2014, with 299 citations. The third-ranked article was a clinical trial by Sillness and Löe, which counted 269 citations [26].

According to the Shapiro-Wilk test, the distribution of data regarding citation count, citation density, and article age was not normal $(p<0.01)$. A significant trend towards a higher citation count with article age was observed $(\mathrm{r}=0.832, p<0.01)$ (Figure 1A). However, a non-significant trend towards an increased citation density with the age of publication was observed $(r=0.176, p=0.129)$ (Figure 1B).

\subsection{Distribution by Year}

The top 100 most-cited articles were published between 1955 [32] and 2014 [30,31]. The most prolific year in terms of publications was 2004, with seven publications, followed by 1997, 1998, 2003, and 2007 with five articles each. The year with most citations was 1998, with 6829 citations, followed by 2004 and 2003, with 6190 and 5879 citations, differently. The decade with most publications $(n=40)$ and citations $(n=35,743)$ was the 2000s (Figure 2A). 

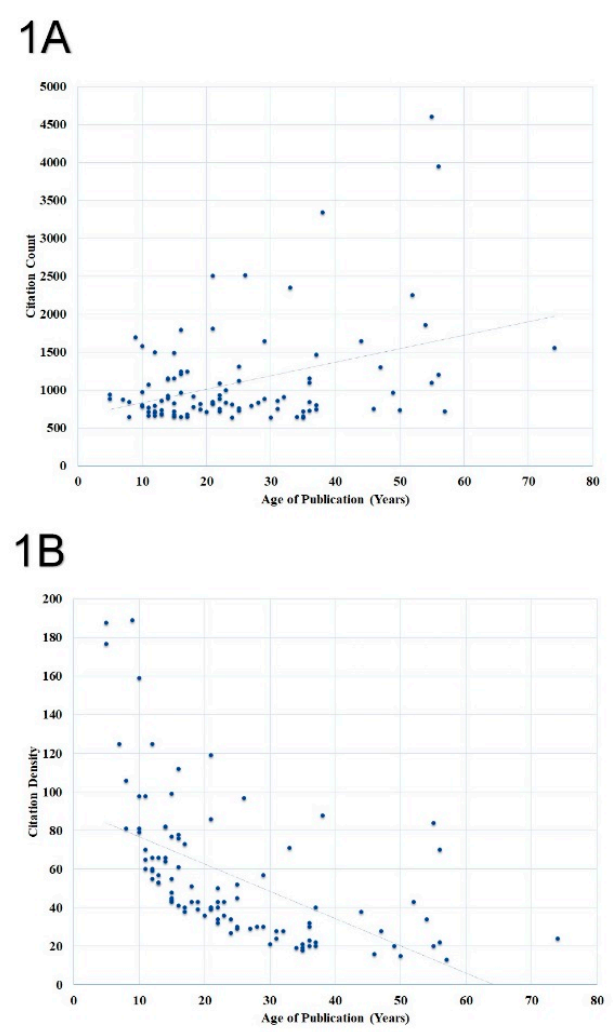

Figure 1. Association of (A) citation count and (B) citation density with the age of publication. The dot represents individual publication and line represents trendline.

\section{A}

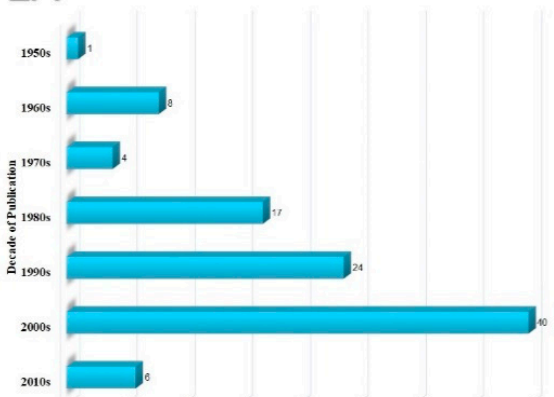

2B

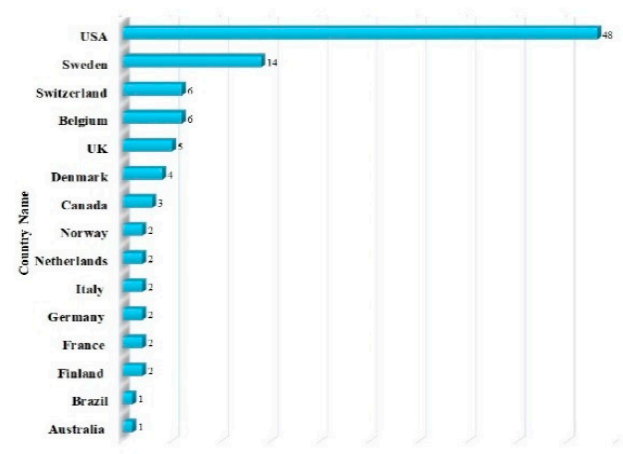

Figure 2. (A) Citation analysis of the top 100 most-cited articles over the decades. (B) The contribution of countries to the top 100 articles. 


\subsection{Contribution of Countries}

The top 100 most-cited publications originated from 15 countries, including Australia, Belgium, Brazil, Canada, Denmark, Finland, France, Germany, Italy, Netherlands, Norway, Sweden, Switzerland, the United Kingdom (UK), and the United States of America (USA) (Figures $2 \mathrm{~B}$ and $\mathrm{3A}$ ). According to the number of publications, most of the articles originated from the United States of America $(n=48)$, followed by Sweden $(n=14)$, Belgium $(n=6)$, Switzerland $(n=6)$, UK $(n=5)$, Denmark $(n=4)$, Canada $(n=3)$, Finland $(n=2)$, France $(n=2)$, Germany $(n=2)$, Italy $(n=2)$, Netherlands $(n=2)$, Norway $(n=2)$, Australia $(n=1)$, and Brazil $(n=1)$.

\subsection{Contribution of Authors}

A total of 264 authors contributed to the top 100 most-cited articles. Many of the articles $(n=84)$ had between one and six authors, but publications with two authors were the most common $(n=27)$. The majority of the contributions were made by Marx RE ( $n=7,8230$ citations), followed by Löe $\mathrm{H}(n=4,12,668)$, Lekholm $\mathrm{U}(n=4,6654)$, Haffajee $\operatorname{AD}(n=4,5313)$, Socransky SS $(n=4,4843)$, Albrektsson T $(n=4,4658)$, De Munck J $(n=4$, 3772), and Genco RJ $(n=4,3014)$ (Table 1 and Figure 3B).

Table 1. Contribution of authors to the top 100 most-cited articles in dentistry.

\begin{tabular}{ccc}
\hline Author Name * & Number of Articles & Citation Count \\
\hline Marx RE & 7 & 8230 \\
Löe H & 4 & 12,668 \\
Lekholm U & 4 & 6654 \\
Haffajee AD & 4 & 5313 \\
Socransky SS & 4 & 4843 \\
Albrektsson T & 4 & 4658 \\
De Munck J & 4 & 3772 \\
Genco RJ & 4 & 3014 \\
Brånemark PI & 3 & 6140 \\
Mehrotra B & 3 & 3183 \\
Ruggiero SL & 3 & 3183 \\
Lambrechts P & 3 & 3156 \\
Van Landuyt K & 3 & 3049 \\
Van Meerbeek B & 3 & 3049 \\
Yoshida Y & 3 & 2620 \\
Sjögren U & 3 & 2444 \\
Sundqvist G & 3 & 2444 \\
Lindhe J & 3 & 2439 \\
Zambon JJ & 3 & 2144 \\
Berglundh T & 3 & 2112
\end{tabular}

* Due to a high number of contributing authors to the top 100 most-cited articles, it was not possible to mention all the authors in a table. Hence, the authors who contributed to $\geq 3$ articles were included in the table.

\subsection{Journal of Publication}

Overall, the top 100 most-cited articles in dentistry were published in both specialized and comprehensive periodicals $(n=31)$ (Table 2 and Figure 3C). The journal with the greatest number of publications was the Journal of Dental Research ( $n=17,17,836$ citations), followed by Journal of Periodontology ( $n=11,12,141)$, Journal of Clinical Periodontology $(n=9$, 8461), Journal of Oral and Maxillofacial Surgery $(n=8,8873)$, Dental Materials $(n=7,6220)$, Journal of Endodontics $(n=5,3927)$, and Periodontology $2000(n=4,3391)$. 
Table 2. List of journals in which the top 100 most-cited articles were published.

\begin{tabular}{|c|c|c|c|c|}
\hline Journal Name & JIF (2019)* & 5-Year JIF * & $\begin{array}{c}\text { No. of } \\
\text { Articles }\end{array}$ & Citation Count \\
\hline J Dent Res & 4.914 & 5.844 & 17 & 17,836 \\
\hline J Periodontol & 3.742 & 3.614 & 11 & 12,141 \\
\hline J Clin Periodontol & 5.241 & 5.213 & 9 & 8461 \\
\hline J Oral Maxillofac Surg & 1.642 & 2.020 & 8 & 8873 \\
\hline Dent Mater & 4.495 & 5.386 & 7 & 6220 \\
\hline J Endod & 3.118 & 3.380 & 5 & 3927 \\
\hline Periodontol 2000 & 7.718 & 8.888 & 4 & 3391 \\
\hline Int J Oral Maxillofac Surg & 2.068 & 2.987 & 3 & 4200 \\
\hline Oral Surg Oral Med Oral Pathol Radiol & 1.601 & 1.810 & 3 & 3345 \\
\hline J Prosthet Dent & 2.444 & 2.727 & 3 & 2915 \\
\hline Acta Odontol Scand & 1.573 & 1.785 & 2 & 8549 \\
\hline Int J Oral Maxillofac Implants & 2.320 & 2.987 & 2 & 3996 \\
\hline Commun Dent Oral Epidemiol & 2.135 & 2.558 & 2 & 2310 \\
\hline J Oral Pathol Med & 2.495 & 2.330 & 2 & 2166 \\
\hline Commun Dent Health & 0.679 & 1.140 & 2 & 2064 \\
\hline J Am Dent Assoc & 2.803 & 2.950 & 2 & 1816 \\
\hline Am J Orthod Dentofac Orthop & 1.960 & 2.405 & 2 & 1814 \\
\hline Clinical Oral Implants Research & 3.723 & 4.044 & 2 & 1723 \\
\hline Eur J Oral Sci & 2.220 & 2.225 & 2 & 1667 \\
\hline Int Dent J & 2.038 & 1.863 & 1 & 1651 \\
\hline Oral Oncol & 3.979 & - & 1 & 1585 \\
\hline Oper Dent & 2.213 & 2.954 & 1 & 1248 \\
\hline Int J Periodontics Restorative Dent & 1.513 & 1.739 & 1 & 968 \\
\hline J Oral Fac Pain Headache & 1.260 & 2.421 & 1 & 941 \\
\hline Implant Dent & 1.452 & 1.606 & 1 & 781 \\
\hline Arch Oral Biol & 1.931 & 2.112 & 1 & 752 \\
\hline J Can Dent Assoc & 1.200 & 0.917 & 1 & 735 \\
\hline J Dent & 3.242 & 4.265 & 1 & 725 \\
\hline Int Endod J & 3.801 & 3.418 & 1 & 721 \\
\hline Int J Prosthod & 1.490 & 1.692 & 1 & 678 \\
\hline J Dent Edu & 1.322 & 1.371 & 1 & 649 \\
\hline
\end{tabular}

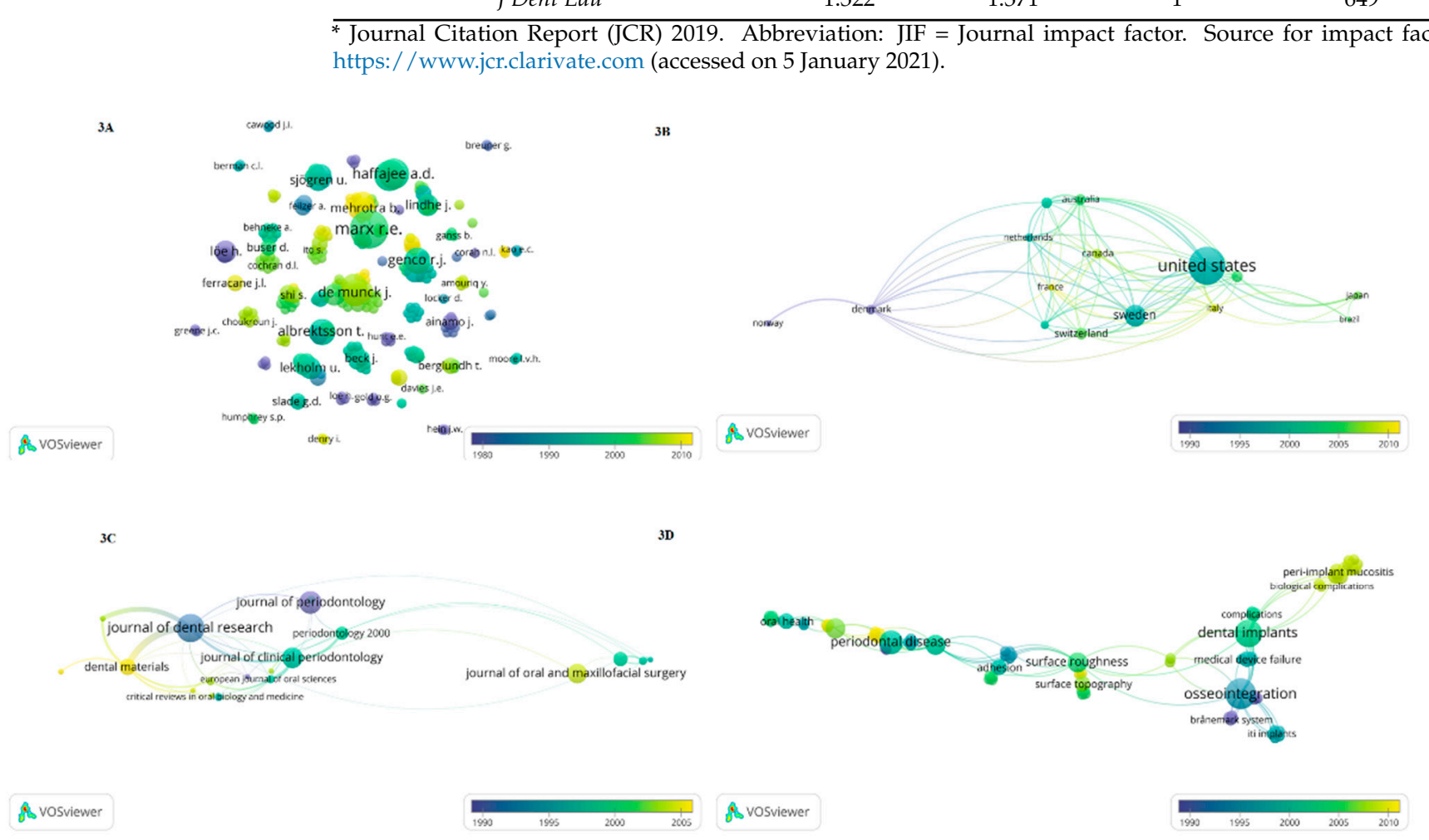

Figure 3. (A) Network visualization per author (Elsevier's Scopus data 1980-2010). (B) Network visualization per count (Elsevier's Scopus data 1990-2010). (C) Network visualization per journal (Elsevier's Scopus data 1990-2010). (D) Network visualization per author keywords (Elsevier's Scopus data 1990-2010). 
A statistically non-significant trend $(p=0.204)$ was observed between a journal age and the number of articles published in that journal. However, a statistically significant trend $(p<0.05)$ was observed between the impact factor of the journal and the number of articles published in that journal.

\subsection{Field of Interest}

For the 100 most-cited articles, the field of interest for the majority were related to Periodontology ( $n=26,32,410$ citations), adhesive restorations $(n=14,11,915)$, implantology $(n=13,15,592)$, oral medicine/pathology $(n=12,12,785)$, endodontics $(n=8$, $5936)$, oral hygiene $(n=8,10,643)$, bone morphology /histology $(n=7,6943)$, oral biology/morphology $(n=4,5862)$, regenerative dentistry $(n=2,2228)$, orthodontics $(n=2$, $1814)$, saliva/biochemistry $(n=1,917)$, pain dysfunction/orofacial pain syndrome $(n=1$, $941)$, dental radiology $(n=1,735)$, and behavior management $(n=1,735)$ (Table 3$)$.

Table 3. Distribution of fields of interest, study designs, and evidence levels of the top 100 most-cited articles.

\begin{tabular}{|c|c|c|c|c|}
\hline Variable & Publications per & Citation Count & Median (min-max) & $p$-Value \\
\hline \multicolumn{5}{|c|}{ Field of Interest } \\
\hline Periodontology & $26 \%$ & 32,410 & $818.5(638-4728)$ & \\
\hline Adhesive Restorations & $14 \%$ & 11,915 & $724(638-1560)$ & \\
\hline Implantology & $13 \%$ & 15,592 & $838(649-3341)$ & \\
\hline Oral Medicine/Pathology & $12 \%$ & 12,785 & $927.5(662-1798)$ & \\
\hline Oral Hygiene & $8 \%$ & 10,643 & $1157.5(717-1311)$ & \\
\hline Endodontics & $8 \%$ & 5936 & $780(656-883)$ & \\
\hline Bone morphology/Histology & $7 \%$ & 6943 & $845(692-1813)$ & \\
\hline Oral Biology/Morphology & $4 \%$ & 5862 & $1450.5(756-2517)$ & $p=0.274$ \\
\hline Regenerative Dentistry (Stem cells) & $2 \%$ & 2228 & $1114(979-1249)$ & \\
\hline Orthodontics & $2 \%$ & 1814 & $907(719-1095)$ & \\
\hline Pain dysfunction/Orofacial pain syndrome & $1 \%$ & 941 & $941(941)$ & \\
\hline Saliva/Biochemistry & $1 \%$ & 917 & $917(917)$ & \\
\hline Behavior Management & $1 \%$ & 735 & $735(735)$ & \\
\hline Dental Radiology & $1 \%$ & 735 & $735(735)$ & \\
\hline \multicolumn{5}{|c|}{ Study Design } \\
\hline Narrative review/Expert opinion & $36 \%$ & 34,628 & $831.5(637-2517)$ & \\
\hline Clinical trial & $24 \%$ & 34,296 & $952(638-4602)$ & \\
\hline Classification or tool for evaluating results & $11 \%$ & 14,072 & 1099 (703-2350), & \\
\hline Systematic review/Meta-analysis & $9 \%$ & 6627 & $713(664-845)$ & \\
\hline In vitro study & $7 \%$ & 7561 & $808(656-1813)$ & \\
\hline Animal study & $4 \%$ & 4063 & $884.5(831-1463)$ & $p=0.145$ \\
\hline New material or technique & $4 \%$ & 3048 & $741.5(655-910)$ & \\
\hline Cohort study & $2 \%$ & 1879 & 939.5 (883-996) & \\
\hline Letter to editor & $1 \%$ & 1798 & $1798(1798)$ & \\
\hline Consensus report & $1 \%$ & 767 & $767(767)$ & \\
\hline Randomized controlled trial & $1 \%$ & 717 & $717(717)$ & \\
\hline
\end{tabular}

\subsection{Methodological Design of the Publication}

The most common methodological design in the top 100 publications was literature review / expert opinion ( $n=36,34,628$ citations), followed by clinical trial $(n=24,34,296)$, classification or tool for assessing results $(n=11,14,072)$, systematic review/meta-analysis ( $n=9,6627)$, in vitro study $(n=7,7561)$, animal study $(n=4,4063)$, new material or technique $(n=4,3048)$, cohort study $(n=2,1879)$, consensus report $(n=1,767)$, randomized controlled trial $(n=1,717)$, and letter to editor $(n=1,1798)$ (Table 3$)$.

\subsection{Evidence Level of Publication}

The top 100 most-cited publications could be classified into all evidence levels (Table 3 ). Most of the articles were within evidence level V ( $n=64,65,937$ citations), followed by 
evidence level IV ( $n=24,34,296)$, evidence level $1(n=9,6627)$, evidence level III $(n=2$, $1879)$, and evidence level II $(n=1,717)$. Among these evidence levels, the total citation counts $(r=-0.226, p=0.078)$ and the citation density $(r=0.082, p=0.633)$ did not vary significantly.

\subsection{Author Keywords}

A total of 538 keywords were identified from the top 100 most-cited articles (Figure 3D). The most frequently used keyword was osseointegration $(n=6)$, followed by dental implants $(n=5)$, periodontal disease $(n=4)$, periodontitis $(n=3)$, review $(n=3)$, surface roughness $(n=3)$, dentin $(n=3)$, epidemiology $(n=3)$, and wound healing $(n=3)$.

\subsection{Comparison with the Bibliometric Analysis by Feijoo et al.}

Table 4 depicts the main differences between the present study and the bibliometric analysis performed by Feijoo et al. [9]. In the current study, for screening and identifying the most-cited articles, the author utilized Scopus as the benchmark database and used Google Scholar to crossmatch the citation data. On the contrary, Feijoo et al. [9] employed the Web of Science as the benchmark database only. A total of 10 bibliometric parameters were evaluated in the current analysis as compared to Feijoo et al. [9] in which 7 bibliometric variables were assessed. For an unknown reason, the journal Acta Odontologica Scandinavica was not included in the study by Feijoo et al. [9]. Interestingly, the 1st and 2nd ranked articles in the present analysis were published in the Acta Odontologica Scandinavica. In the present analysis, 48 articles present in the study conducted by Feijoo et al. [9], could secure their position. In the present analysis, an increase of almost two-fold in the total citation counts of the top 100 most-cited articles (113,482 citations) was observed as compared to Feijoo et al. [9] (52,635 citations). According to the Web of Science, the range of citation counts in the present study varied between 3 and 4321, as compared to Feijoo et al. [9] in which the range was between 326 and 2050. According to the Web of Science, 4 and 35 articles could secure $\geq 1000$ and $\geq 500$ citations respectively, in the study conducted by Feijoo et al. [9]. However, in the current analysis, 33 and 100 articles secured $\geq 1000$ and $\geq 500$ citations, respectively. The decade with the majority of publications was the $2000 \mathrm{~s}$ $(40 \%)$ in the present analysis as compared to the study by Feijoo et al. [9] in which the 1980s was the most productive decade in terms of the number of top-cited articles $(26 \%)$. In the present study, publications having two authors (27\%) were the most common as compared to the study by Feijoo et al. [9] in which single-author papers (25\%) were the most frequent. The biggest contribution was made by Marx RE (7\%) in the current study, as compared to Feijoo et al. [9] in which Socransky SS made the biggest contribution (9\%). The Journal of Dental Research (17\%) was the most prolific in the current analysis, compared to the Journal of Clinical Periodontology (20\%) in the Feijoo et al. study [9]. In both the analyses, articles related to periodontology were the most cited ones. In terms of study design, narrative review/expert opinion (36\%) was the most commonly cited methodological design in the current study as compared to an analysis by Feijoo et al. [9] in which case series (22\%) was the most frequently cited study design. In terms of evidence level of the publications, articles having evidence level V were the most cited in both the studies. 
Table 4. Comparative analysis of the differences between the present study and Feijoo et al. [9].

\begin{tabular}{|c|c|}
\hline Feijoo et al. [9] & Present Study \\
\hline \multicolumn{2}{|c|}{ Database Employment } \\
\hline $\begin{array}{l}\text { Clarivate Analytics' Web of Science } \\
\text { (Benchmark) }\end{array}$ & Elsevier's Scopus (Benchmark) \\
\hline- & Google Scholar \\
\hline \multirow{2}{*}{\multicolumn{2}{|c|}{ Assessed Bibliometric Parameters }} \\
\hline & \\
\hline 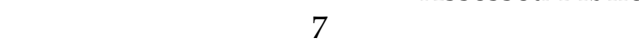 & 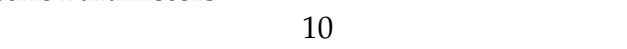 \\
\hline \multicolumn{2}{|c|}{ Citation Count } \\
\hline Total citation count: & Total citation count: \\
\hline $52,635(\mathrm{WoS})$ & $113,482(\mathrm{ES})$ \\
\hline- & $214,642(\mathrm{GS})$ \\
\hline \multicolumn{2}{|r|}{ ( ) } \\
\hline Range of citation count: & Range of citation count: \\
\hline 326-2050 (WoS) & 638 and $4728(\mathrm{ES})$ \\
\hline- & 138 and 8281 (GS) \\
\hline \multicolumn{2}{|r|}{ 20 } \\
\hline Articles with $\geq 1000$ citations: 4 & Articles with $\geq 1000$ citations: 33 \\
\hline Articles with $\geq 500$ citations: 35 & Articles with $\geq 500$ citations: 100 \\
\hline \multicolumn{2}{|c|}{ Authorship } \\
\hline Articles with single author: 25 & Articles with single author: 20 \\
\hline Articles with two authors: 18 & Articles with two authors: 27 \\
\hline Articles with more than 6 authors: 12 & Articles with more than 6 authors: 16 \\
\hline Leading author: Socransky SS $(n=9)$ & Leading author: Marx RE $(n=7)$ \\
\hline \multicolumn{2}{|c|}{ Publication Year } \\
\hline Decade with most publications: 1980s (26\%) & Decade with most publications: 2000s (40\%) \\
\hline \multicolumn{2}{|c|}{ Field of Interest } \\
\hline 1 st $=$ Periodontology $(43 \%)$ & 1st $=$ Periodontology $(26 \%)$ \\
\hline 2nd = Implantology $(11 \%)$ & 2 nd $=$ Adhesive restorations $(14 \%)$ \\
\hline $3 \mathrm{rd}=$ Adhesive restorations $(8 \%)$ & 3rd = Implantology $(13 \%)$ \\
\hline \multicolumn{2}{|c|}{ Study Design } \\
\hline 1 st $=$ Cases series $(22 \%)$ & 1 st $=$ Narrative review $/$ expert opinion $(36 \%)$ \\
\hline 2nd = Narrative review / expert opinion (19\%) & 2nd $=$ Clinical trial $(24 \%)$ \\
\hline $\begin{array}{c}\text { 3rd }=\text { Classifications or tools for evaluating } \\
\text { results }(13 \%)\end{array}$ & $\begin{array}{c}3 \mathrm{rd}=\text { Classifications or tools for evaluating } \\
\text { results }(11 \%)\end{array}$ \\
\hline \multicolumn{2}{|c|}{ Evidence Level } \\
\hline$E L V=54 \%$ & $\mathrm{EL} \mathrm{V}=64 \%$ \\
\hline \multicolumn{2}{|c|}{ Journal of Publication } \\
\hline Total number of journals: 22 & Total number of journals: 32 \\
\hline 1st $=$ Journal of Clinical Periodontology $(20 \%)$ & 1 st $=$ Journal of Dental Research $(17 \%)$ \\
\hline 2nd $=$ Journal of Periodontology $(18 \%)$ & 2nd = Journal of Periodontology (11\%) \\
\hline 3rd = Journal of Dental Research $(16 \%)$ & 3rd = Journal of Clinical Periodontology $(9 \%)$ \\
\hline
\end{tabular}

\section{Discussion}

Authors' bibliometric analysis allows readers to gain historical insight and development of a particular specialty by identifying and analyzing the most-cited publications that could assist researchers in understanding the emerging themes and future trends for a particular discipline [33-35]. For instance, the number of citations a publication receives could indicate other researchers' interest in using the information for their research. Highly cited articles could display a tendency in clinical practice and may therefore be considered to produce greater research and clinical interest in the reported disciplines [36]. Being "most-cited" article reflects its more frequent contribution to the studies published afterward; however, this characteristic alone does not provide sufficient information regarding its current impact and scientific quality, as the main motive of citers in the selection of reference is in establishing the utility within research, rather than scientific quality [37-39]. As per the definition of a "classic article", all the articles included in this study are called "classic articles" [8,22,23]. 
The accuracy of bibliometric analyses might be negatively influenced by the limitations of the search engine used. Elsevier's Scopus, Google Scholar, and Clarivate Analytics' Web of Science may differ quantitatively or qualitatively concerning the citation count of a publication depending upon the discipline of the study [12,16,40], journals [41], and years [42] in which they were published. Additionally, some publications might not be available in all of these search engines $[16,25,43,44]$. There were several reasons for not selecting either Google Scholar or Web of Science databases as the benchmark for this analysis. For instance, Google Scholar includes citations from non-scholarly publications including dissertations and thesis, conference papers, technical reports, books, and preprints, which may affect the analysis of the most-cited articles when the target is more specific, as in the present study [44]. However, in Web of Science, missing references are a considerable issue [40], which is a likely reason why Buonocore's highly cited paper [32] in Google Scholar (4367 citations) and Scopus (1560 citations) was so under cited in Web of Science (427 citations). Similarly, Löe's [45] highly cited article in Google Scholar (4019 citations) and Scopus (2257 citations) received only 3 citations in Web of Science. It is important to note that both the abovementioned articles were present in the Web of Science "All Databases" section, and not in the Web of Science "Core Collection". One of the several reasons for selecting Scopus as the benchmark database was that it combines the features of PubMed and Web of Science. These combined characteristics enable improved utility for medical literature research and academic requirements (i.e., citation analysis) [43]. Moreover, Scopus is regarded as the largest citation and abstract search engine of peer-reviewed literature. It is devised to aid researchers in not only accessing scientific information but screening literature for analysis [46], and it has been employed in numerous published bibliometric analyses $[25,47,48]$. In Scopus, citation analysis is faster and includes more publications than that of Web of Science [49]. In a recently performed study for evaluating the accuracy of citation information in Web of Science and Scopus databases, the authors stated that the former database includes $16.7 \%$ incorrect references, also called phantom references, $26.7 \%$ error in references (i.e., incorrect volume number or publication year), and $55 \%$ missing references [44]. Overall, the author thought Scopus to be the better tool for this study as compared to the similar study by Feijoo et al. [9] that employed Web of Science as the benchmark database.

In many bibliometric studies, it was reported that relevant studies were distributed among journals following Bradford's law [49-51]. According to this bibliometric law, a few prolific journals account for a considerable percentage of all publications in a given discipline [52]. The studies published in these core journals are more probable to be referred to most commonly by successive articles [53]. Interestingly, in this study, the journal distribution pattern of the most-cited publications does not completely fit this law, as the list also features journals such as the Acta Odontologica Scandinavica and the Journal of Dental Research, which are not considered as the specialized journals in the field of periodontics and adhesive restorations respectively but published few of top-cited articles. Hence, the application of this law for conducting bibliometric analysis in some disciplines may cause inaccurate inferences. In this study, a statistically significant association was found between the number of the most-cited articles published in a journal and the impact factor of that journal. This finding is in accordance with the findings of some bibliometric studies [52-55], but contrary to those of several others [54,56].

As with several "most-cited" publications in dentistry [8,53-58], this study reported that most of the most-cited articles in dentistry originated from the United States. This significant contribution can be attributed to a larger scientific population, active researchers, and ample financial resources [10,17,59-61]. Additionally, to unparalleled research work, an increased tendency among authors to cite articles originating from the US has been observed $[17,62]$. It is noteworthy that approximately $47 \%$ of the most cited dentistry articles, including the 1st and 2nd, ranked articles in this study, originated from European institutions, despite their small population size. Importantly, a lack of multicenter studies was noticeable, reflecting a need to escalate international collaboration. 
Overall, after the US, European countries, including Sweden, Belgium, Switzerland, UK, and Denmark, have been prominent in this list of contributing authors. Additionally, to this study, several other bibliometric analyses have reported that authors from Asia, Africa, and the Middle East, whether being the first or the corresponding author made a negligible contribution to what could be considered a top-cited article $[17,60,63,64]$. Potential reasons might include language barriers, gaps in conducting research, and professional networking, as well as limited information access [65]. International organizations such as the World Health Organization [WHO] and the United Nations [UN] could play a vital role in bolstering these health care developments.

The particular subject area of the highly cited papers fluctuates from one decade to another. Overall, in the present study, there was a domination of articles related to periodontology, specifically on the topic of microbiology, although other disciplines of dentistry, including adhesive restorations and implantology, have been progressively incorporated. A considerable portion of our analysis comprised of narrative reviews $(36 \%)$. It might be argued that this category of publication does not follow the concept of reproducible science [66] as a systematic review does [67]. Interestingly, the findings of this study are in opposition to this concept of being a narrative review or systematic review. When compared to the baseline references, randomized controlled trials, a narrative review appeared to secure higher citations than a systematic review. One possible explanation might be that narrative reviews aim to explain the mechanisms of diseases or hypothesis generation; hence, a systematic method to synthesize the evidence in these cases may be irrelevant. Furthermore, as these narrative reviews are authored by the experts in the respective specialty and supported by reputed institutions, readers tend to believe that these articles are not overly sensitive to bias. Nevertheless, in opposition to the previous concerns about the non-reproducibility of narrative reviews, future research is therefore required to explain the extent to which scientific advancement is encouraged through systematic (in comparison with narrative) reviews. Interestingly, the dental journal with the current highest impact factor, Periodontology 2000, is focused on publishing narrative reviews. After narrative reviews, clinical trials are the most frequently cited study design $(24 \%)$. This finding is in agreement with the results of several other bibliometric studies conducted in other medical fields including orthopedic surgery [68], anesthesia [59], and general surgery [60].

A distinctive characteristic of this analysis was that it included 10 evidence level-1 studies, including systematic reviews, meta-analyses, and randomized controlled trials. These findings do not coincide with the findings of several other bibliometric analyses performed on various specialties within dentistry and medicine $[16,25,68-70]$. Recently, these high evidence level studies have been performed and are securing high citations, despite only being published in recent years [71]. Such reports are useful for facilitating decision-making, directing practice, and advancing research, so a high number of such studies in the current study is not surprising and provides further proof of the maturation of the discipline [72].

This bibliometric analysis has several limitations. First, for a given research field, many factors may influence the citation count, including the age of the publication, journal of publication, the reputation of author, institution, and country of origin as well as the original language. Second, the analysis of self-citations and citations in textbooks and lectures was not performed. Moreover, the fact that some authors may be inclined to cite articles from a particular journal in which they intend to publish an article [73]. Third, the analysis of the contributing countries was based on the address of the corresponding author. A statistical bias may occur once the address of the corresponding author is changed [74]. Furthermore, for corresponding authors working in multiple institutions, we only considered the first institution. 


\section{Materials and Methods}

\subsection{Search Strategy}

A total of 91 journals included in the category "Dentistry, Oral Surgery, and Medicine" in the database of the 2019 edition of the Journal Citation Report: Science Edition, a section of the Clarivate Analytics (https:/ / www.jcr.clarivate.com) (accessed on 1 January 2021) were selected. An electronic literature search on Scopus (https://www.scopus. com) (accessed on 1 January 2021) database was performed on 1 January 2021. The journals American Journal of Orthodontics, now called the American Journal of Orthodontics and Dentofacial Orthopedics, the International Journal of Oral Surgery, now called as the International Journal of Oral and Maxillofacial Surgery, and Critical Reviews in Oral Biology and Medicine, now affiliated with the Journal of Dental Research, were also reviewed.

As the search strategy for each journal, the journal's title was written in the source title' section without any restriction of language, publication year, and study design of the article. Using the 'documents' tool of Scopus, the citation counts of all the articles published in all dentistry journals were identified.

\subsection{Article Selection}

According to the selected database, 336,381 articles were retrieved, out of which, the top 100 most-cited publications were further selected for this bibliometric analysis. The top 100 most-cited articles were selected and ranked based on their citation count. After ranking these articles, their cross-matching was performed with the citation data from Google Scholar to evaluate any fluctuation in citation counts.

\subsection{Data Extraction and Bibliometric Variables}

A total of 100 articles were included in this study, and their complete text was downloaded. The following bibliometric variables were extracted: publication title, citation count, current citation count (i.e., the total number of citation count collected by an article in 2020) [75], citation density (i.e., the total number of citation count/age of publication) [75], publication year, authorship, country of origin, study design, the field of interest, evidence level, and journal of publication.

Based on the study design, the articles were categorized as animal study, classification or tool for assessing the results, case-control study, cohort study, consensus report, in vitro study, letter to the editor, narrative review/expert opinion, new material or technique, randomized controlled trial, and systematic review/meta-analysis. Based on the field of interest, the articles were classified as adhesive restorations/dental materials, bone morphology/histology, behavior management, dental caries, endodontics, implantology, oral biology/morphology, oral pathology/medicine, oral radiology, orthodontics, oral hygiene, periodontology, pediatric dentistry, pain dysfunction/orofacial pain syndrome, regenerative dentistry, and saliva/biochemistry.

\subsection{Data and Statistical Analysis}

The Visualization of Similarities (VOSviewer) software (Centre for Science and Technology Studies, Leiden University, Leiden, The Netherlands) [76] was employed to visually analyze the registers separately, drawing a network of links among prominent authors, contributing countries, publishing journals, and author keywords to identify the strongest link of the net. The reason for selecting this software to draw and represent large networks from bibliometric information among other software, including Pajek or Gephi, is the remarkable display quality, the choice of demonstrating the density of links, and the probability of creating overlay maps adding data batches. Moreover, this software has been employed in several bibliometric analyses [75,77-80]. The characteristics are relevant for performing our bibliometric analysis.

Descriptive and bivariate analyses were performed using a statistical software package, i.e., IBM SPSS Statistics version 24.0 (IBM, Chicago, IL, USA). To assess the normality of the data, the Shapiro-Wilk test was conducted. Mean (standard deviation) or median 
(interquartile range) were calculated based on normality and distribution of data. To evaluate the median differences between the independent groups, the Kruskal-Wallis test was performed. Post hoc testing was performed to assess the median differences within each group. Any decrease or increase in the time-dependent trends was analyzed by performing the Mann-Kendall trend test. The Spearman-rank test was performed to assess the correlation between the publication count of the journal and the age of the journal. A value of $p<0.05$ was considered statistically significant.

\section{Conclusions}

An appropriate selection of search engine and search strategy are extremely important to conduct a thorough bibliometric analysis. In this study, changing the search database resulted in several prominent differences when compared with the outcomes of a similar analysis published by Feijoo et al. [9] in 2014. The current study reported that narrative reviews/expert opinions related to periodontology having evidence level $\mathrm{V}$ were the most-cited articles in dentistry.

Supplementary Materials: The following are available online at https:/ /www.mdpi.com/2227-903 2/9/3/356/s1, Table S1: The list of the top 100 most-cited articles published in the dentistry.

Author Contributions: F.Y.A.; Conceptualization; Data curation; Formal analysis; Investigation; Methodology; Writing—original draft. E.K.; Conceptualization; Resources; Software; Supervision; Validation; Writing-review and editing. M.T.; Formal analysis; Methodology; Resources; Supervision; Writing-review and editing. All authors have read and agreed to the published version of the manuscript.

Funding: The authors would like to acknowledge the financial support provided to Faris Asiri by the Deanship of Scientific Research at King Faisal University, under Nasher's Track 206003.

Institutional Review Board Statement: Not applicable.

Informed Consent Statement: Not applicable.

Acknowledgments: The authors would like to acknowledge the University of Western Australia and the College of Dentistry, King Faisal University for their ongoing support.

Conflicts of Interest: The authors declare no conflict of interest.

\section{References}

1. Pulgar, R.; Jiménez-Fernández, I.; Jiménez-Contreras, E.; Torres-Salinas, D.; Lucena-Martín, C. Trends in World Dental Research: An overview of the last three decades using the Web of Science. Clin. Oral Investig. 2013, 17, 1773-1783. [CrossRef] [PubMed]

2. Jayaratne, Y.S.N.; Zwahlen, R.A. The evolution of dental journals from 2003 to 2012: A bibliometric analysis. PLoS ONE 2015, 10, e0119503. [CrossRef] [PubMed]

3. Olk, P.; Griffith, T.L. Creating and disseminating knowledge among organizational scholars: The role of special issues. Organ. Sci. 2004, 15, 120-129. [CrossRef]

4. Ring, M.E. The world's first dental journal. Compend. Contin. Educ. Dent. 1986, 7, 648-650.

5. Raja, M.; Ravichandran, T. Recognizing self-citations via citation quality analysis. J. Theor. Appl. Inf. Technol. 2014, 69, 113-126.

6. Perazzo, M.F.; Otoni, A.L.C.; Costa, M.S.; Granville-Granville, A.F.; Paiva, S.M.; Martins-Júnior, P.A. The top 100 most-cited papers in Paediatric Dentistry journals: A bibliometric analysis. Int. J. Paediatr. Dent. 2019, 29, 692-711. [CrossRef]

7. De la Flor-Martínez, M.; Galindo-Moreno, P.; Sánchez-Fernández, E.; Piattelli, A.; Cobo, M.J.; Herrera-Viedma, E. H-classic: A new method to identify classic articles in Implant Dentistry, Periodontics, and Oral Surgery. Clin. Oral Implants Res. 2016, 27, 1317-1330. [CrossRef]

8. Fardi, A.; Kodonas, K.; Gogos, C.; Economides, N. Top-cited articles in endodontic journals. J. Endod. 2011, 37, 1183-1190. [CrossRef]

9. Feijoo, J.F.; Limeres, J.; Fernández-Varela, M.; Ramos, I.; Diz, P. The 100 most cited articles in dentistry. Clin. Oral Investig. 2014, 18, 699-706. [CrossRef] [PubMed]

10. Tarazona, B.; Lucas-Dominguez, R.; Paredes-Gallardo, V.; Alonso-Arroyo, A.; Vidal-Infer, A. The 100 most-cited articles in orthodontics: A bibliometric study. Angle Orthod. 2018, 88, 785-796. [CrossRef]

11. Corbella, S.; Francetti, L.; Taschieri, S.; Weinstein, R.; Del Fabbro, M. Analysis of the 100 most-cited articles in periodontology. J. Investig. Clin. Dent. 2016, 8, e12222. [CrossRef] [PubMed] 
12. Fardi, A.; Kodonas, K.; Lillis, T.; Veis, A. Top-Cited Articles in Implant Dentistry. Int. J. Oral Maxillofac. Implant. 2017, 32, 555-564. [CrossRef] [PubMed]

13. Praveen, G.; Chaithanya, R.; Alla, R.K.; Shammas, M.; Abdurahiman, V.; Anitha, A. The 100 most cited articles in prosthodontic journals: A bibliometric analysis of articles published between 1951 and 2019. J. Prosthet. Dent. 2020, 123, 724-730. [CrossRef]

14. Aslam-Pervez, N.; Lubek, J.E. Most cited publications in oral and maxillofacial surgery: A bibliometric analysis. Oral Maxillofac. Surg. 2018, 22, 25-37. [CrossRef]

15. Jafarzadeh, H.; Sarraf Shirazi, A.; Andersson, L. The most-cited articles in dental, oral, and maxillofacial traumatology during 64 years. Dent. Traumatol. 2015, 31, 350-360. [CrossRef] [PubMed]

16. Baldiotti, A.L.P.; Amaral-Freitas, G.; Barcelos, J.F.; Freire-Maia, J.; de França Perazzo, M.; Freire-Maia, F.B.; Paiva, S.M.; Ferreira, F.M.; Martins-Júnior, P.A. The Top 100 Most-Cited Papers in Cariology: A Bibliometric Analysis. Caries Res. 2020, 18, 1-9.

17. Hassona, Y.; Qutachi, T. A bibliometric analysis of the most cited articles about squamous cell carcinoma of the mouth, lips, and oropharynx. Oral Surg. Oral Med. Oral Pathol. Oral Radiol. 2019, 128, 25-32.e6. [CrossRef] [PubMed]

18. Gondivkar, S.M.; Sarode, S.C.; Gadbail, A.R.; Gondivkar, R.S.; Chole, R.; Sarode, G.S. Bibliometric analysis of 100 most cited articles on oral submucous fibrosis. J. Oral Pathol. Med. 2018, 47, 781-787. [CrossRef]

19. Liu, W.; Zhang, Y.; Wu, L.; Yang, X.; Shi, L. Characteristics and trends of oral leukoplakia research: A bibliometric study of the 100 most cited articles. Medicine 2019, 98, e16293. [CrossRef]

20. Zhang, Q.; Yue, Y.; Shi, B.; Yuan, Z. A bibliometric analysis of cleft lip and palate-related publication trends from 2000 to 2017. Cleft Pal. Craniofac. J. 2019, 56, 658-669. [CrossRef]

21. Diniz-Freitas, M.; Pena-Cristobal, M.; Pérez-López, D.; Lago-Méndez, L.; Fernández-Feijoo, J.; Limeres-Posse, J. Bibliometric analysis of medication-related osteonecrosis of the jaw: High citation rates but low evidence. J. Oral Maxillofac. Surg. 2019, 77, 1655.e1-1655.e17. [CrossRef]

22. Ponce, F.A.; Lozano, A.M. Highly cited works in neurosurgery. Part I: The 100 top-cited papers in neurosurgical journals: A review. J. Neurosurg. 2010, 112, 223-232. [CrossRef] [PubMed]

23. Ponce, F.A.; Lozano, A.M. The most cited works in Parkinson's disease. Mov. Disord. 2011, 26, 380-390. [CrossRef]

24. Mattos, F.d.F.; Perazzo, M.F.; Vargas-Ferreira, F.; Martins-Júnior, P.A.; Paiva, S.M. Top 100 most-cited papers in core dental public health journals: Bibliometric analysis. Commun. Dent. Oral Epidemiol. 2021, 49, 40-46. [CrossRef]

25. Ahmad, P.; Asif, J.A.; Alam, M.K.; Slots, J. A bibliometric analysis of Periodontology 2000. Periodontology 2000 2020, 82, $286-297$. [CrossRef] [PubMed]

26. Silness, J.; Löe, H. Periodontal disease in pregnancy II. Correlation between oral hygiene and periodontal condition. Acta Odontol. Scand. 1964, 22, 121-135. [CrossRef]

27. Löe, H.; Silness, J. Periodontal disease in pregnancy I. Prevalence and severity. Acta Odontol. Scand. 1963, 21, 533-551. [CrossRef]

28. Adell, R.; Lekholm, U.; Rockler, B.; Brånemark, P.-I. A 15-year study of osseointegrated implants in the treatment of the edentulous jaw. Int. J. Oral Surg. 1981, 10, 387-416. [CrossRef]

29. Guo, S.A.; DiPietro, L.A. Factors affecting wound healing. J. Dent. Res. 2010, 89, 219-229. [CrossRef]

30. Schiffman, E.; Ohrbach, R.; Truelove, E.; Look, J.; Anderson, G.; Goulet, J.-P.; List, T.; Svensson, P. Diagnostic criteria for temporomandibular disorders (DC/TMD) for clinical and research applications: Recommendations of the International RDC/TMD Consortium Network and Orofacial Pain Special Interest Group. J. Oral Facial Pain Headache 2014, 28, 6-27. [CrossRef]

31. Ruggiero, S.L.; Dodson, T.B.; Fantasia, J.; Goodday, R.; Aghaloo, T.; Mehrotra, B.; O'Ryan, F. American Association of Oral and Maxillofacial Surgeons position paper on medication-related osteonecrosis of the jaw-2014 update. J. Oral Maxillofac. Surg. 2014, 72, 1938-1956. [CrossRef] [PubMed]

32. Buonocore, M. A simple method of increasing the adhesion of acrylic filling materials to enamel. J. Dent. Res. 1955, 34, 849-853. [CrossRef] [PubMed]

33. Huang, Z.; Chen, H.; Liu, Z. The 100 top-cited systematic reviews/meta-analyses in central venous catheter research: A PRISMA-compliant systematic literature review and bibliometric analysis. Intensiv. Crit. Care Nurs. 2020, 57, 102803. [CrossRef] [PubMed]

34. Chen, X.; Yang, K.; Xu, Y.; Li, K. Top-100 highest-cited original articles in inflammatory bowel disease: A bibliometric analysis. Medicine 2019, 98, e15718. [CrossRef]

35. Faggion Junior, C.M.; Trescher, A.-L.; Listl, S. The 300 most cited articles published in periodontology. Clin. Oral Investig. 2017, 21, 2021-2028. [CrossRef]

36. Eyre-Walker, A.; Stoletzki, N. The assessment of science: The relative merits of post-publication review, the impact factor, and the number of citations. PLoS Biol. 2013, 11, e1001675. [CrossRef]

37. Khan, M.S.; Usman, M.S.; Fatima, K.; Hashmani, N.; Siddiqi, T.J.; Riaz, H.; Khan, A.R.; Khosa, F. Characteristics of Highly Cited Articles in Interventional Cardiology. Am. J. Cardiol. 2017, 120, 2100-2109. [CrossRef] [PubMed]

38. Seglen, P.O. Citations and journal impact factors: Questionable indicators of research quality. Allergy 1997, 52, 1050-1056. [CrossRef]

39. Kulkarni, A.V.; Aziz, B.; Shams, I.; Busse, J.W. Comparisons of citations in Web of Science, Scopus, and Google Scholar for articles published in general medical journals. JAMA 2009, 302, 1092-1096. [CrossRef] [PubMed]

40. Bakkalbasi, N.; Bauer, K.; Glover, J.; Wang, L. Three options for citation tracking: Google Scholar, Scopus and Web of Science. Biomed. Digit. Libr. 2006, 3, 7. [CrossRef] 
41. Falagas, M.; Pitsouni, E.; Malietzis, G. Pappas, G2008Comparison of PubMed, Scopus, Web of Science, and Google Scholar: Strengths and weaknesses. FASEB J. 2007, 22, 338-342. [CrossRef]

42. Harzing, A.-W.K.; Van der Wal, R. Google Scholar as a new source for citation analysis. Ethic Sci. Environ. Politics 2008, 8, 61-73. [CrossRef]

43. van Eck, N.J.; Waltman, L. Accuracy of citation data in Web of Science and Scopus. arXiv 1906, arXiv:190607011. preprint.

44. Löe, H. The gingival index, the plaque index and the retention index systems. J. Periodontol. 1967, 38, 610-616. [CrossRef]

45. Yahya Asiri, F.; Kruger, E.; Tennant, M. Global Dental Publications in PubMed Databases between 2009 and 2019-A Bibliometric Analysis. Molecules 2020, 25, 4747. [CrossRef] [PubMed]

46. Walsh, C.; Lydon, S.; Byrne, D.; Madden, C.; Fox, S.; O'Connor, P. The 100 most cited articles on healthcare simulation: A bibliometric review. Simul. Healthc. 2020, 13, 211-220. [CrossRef] [PubMed]

47. Brinjikji, W.; Klunder, A.; Kallmes, D.F. The 100 most-cited articles in the imaging literature. Radiology 2013, 269, 272-276. [CrossRef] [PubMed]

48. Shuaib, W.; Acevedo, J.N.; Khan, M.S.; Santiago, L.J.; Gaeta, T.J. The top 100 cited articles published in emergency medicine journals. Am. J. Emerg. Med. 2015, 33, 1066-1071. [CrossRef]

49. Shuaib, W.; Costa, J.L. Anatomy of success: 100 most cited articles in diabetes research. Ther. Adv. Endocrinol. Metab. 2015, 6, 163-173. [CrossRef]

50. Brookes, B.C. Bradford's law and the bibliography of science. Nat. Cell Biol. 1969, 224, 953-956. [CrossRef]

51. Usman, M.S.; Siddiqi, T.J.; Khan, M.S.; Fatima, K.; Butler, J.; Manning, W.J.; Khosa, F. A scientific analysis of the 100 citation classics of valvular heart disease. Am. J. Cardiol. 2017, 120, 1440-1449. [CrossRef]

52. Liu, W.; Ma, L.; Song, C.; Li, C.; Shen, Z.; Shi, L. Research trends and characteristics of oral lichen planus: A bibliometric study of the top-100 cited articles. Medicine 2020, 99, e18578. [CrossRef]

53. Y1lmaz, B.; Dinçol, M.E.; Yalçın, T.Y. A bibliometric analysis of the 103 top-cited articles in endodontics. Acta Odontol. Scand. 2019, 77, 574-583. [CrossRef]

54. Gogos, C.; Kodonas, K.; Fardi, A.; Economides, N. Top 100 cited systematic reviews and meta-analyses in dentistry. Acta Odontol. Scand. 2019, 78, 87-97. [CrossRef]

55. Martin, M.; Lipani, E.; Alvarado Lorenzo, A.; Aiuto, R.; Garcovich, D. Trending topics in orthodontics research during the last three decades: A longitudinal bibliometric study on the top-cited articles. Orthod. Craniofac. Res. 2020, 23, 462-470. [CrossRef] [PubMed]

56. Gondivkar, S.M.; Sarode, S.C.; Gadbail, A.R.; Gondivkar, R.S.; Choudhary, N.; Patil, S. Citation classics in cone beam computed tomography: The 100 top-cited articles. Int. J. Dent. 2018, 2018, 1-6. [CrossRef] [PubMed]

57. Aksoy, U.; Küçük, M.; Versiani, M.; Orhan, K. Publication trends in micro-CT endodontic research: A bibliometric analysis over a 25-year period. Int. Endod. J. 2021, 54, 343-353. [CrossRef] [PubMed]

58. Baltussen, A.; Kindler, C.H. Citation classics in anesthetic journals. Anesthesia Analg. 2004, 98, 443-451. [CrossRef] [PubMed]

59. Paladugu, R.; Schein, M.; Gardezi, S.; Wise, L. One hundred citation classics in general surgical journals. World J. Surg. 2002, 26, 1099-1105. [CrossRef]

60. Brandt, J.S.; Downing, A.C.; Howard, D.L.; Kofinas, J.D.; Chasen, S.T. Citation classics in obstetrics and gynecology: The 100 most frequently cited journal articles in the last 50 years. Am. J. Obstet. Gynecol. 2010, 203, 355.e1-355.e7. [CrossRef]

61. Campbell, F.M. National bias: A comparison of citation practices by health professionals. Bull. Med. Libr. Assoc. 1990, 78, 376-382.

62. Baltussen, A.; Kindler, C.H. Citation classics in critical care medicine. Intensive Care Med. 2004, 30, 902-910. [CrossRef] [PubMed]

63. Fenton, J.; Roy, D.; Hughes, J.; Jones, A. A century of citation classics in otolaryngology-head and neck surgery journals. J. Laryngol. Otol. 2002, 116, 494-498. [CrossRef]

64. Uthman, O.A.; Okwundu, C.I.; Wiysonge, C.S.; Young, T.; Clarke, A. Citation classics in systematic reviews and meta-analyses: Who wrote the top 100 most cited articles? PLoS ONE 2013, 8, e78517. [CrossRef] [PubMed]

65. Casadevall, A.; Fang, F.C. Reproducible science. Infect. Immun. 2010, 78, 4972-4975. [CrossRef] [PubMed]

66. Cook, D.J.; Mulrow, C.D.; Haynes, R.B. Systematic reviews: Synthesis of best evidence for clinical decisions. Ann. Intern. Med. 1997, 126, 376-380. [CrossRef] [PubMed]

67. Lefaivre, K.A.; Shadgan, B.; O’Brien, P.J. 100 most cited articles in orthopaedic surgery. Clin. Orthop. Relat. Res. 2011, 469, 1487-1497. [CrossRef] [PubMed]

68. Ahmad, P.; Dummer, P.; Noorani, T.; Asif, J. The top 50 most-cited articles published in the International Endodontic Journal. Int. Endod. J. 2019, 52, 803-818. [CrossRef]

69. Hui, J.; Han, Z.; Geng, G.; Yan, W.; Shao, P. The 100 top-cited articles in orthodontics from 1975 to 2011. Angle Orthod. 2013, 83, 491-499. [CrossRef]

70. Moher, D.; Liberati, A.; Tetzlaff, J.; Altman, D.G. Preferred Reporting Items for Systematic Reviews and Meta-Analyses: The PRISMA Statement. Ann. Intern. Med. 2009, 151, 264-269. [CrossRef]

71. Swingler, G.H.; Volmink, J.; Ioannidis, J.P. Number of published systematic reviews and global burden of disease: Database analysis. BMJ 2003, 327, 1083-1084. [CrossRef]

72. Zhao, X.; Guo, L.; Lin, Y.; Wang, H.; Gu, C.; Zhao, L.; Tong, X. The top 100 most cited scientific reports focused on diabetes research. Acta Diabetol. 2016, 53, 13-26. [CrossRef] 
73. Zhang, Y.; Huang, J.; Du, L. The top-cited systematic reviews/meta-analyses in tuberculosis research: A PRISMA-compliant systematic literature review and bibliometric analysis. Medicine 2017, 96, e4822. [CrossRef]

74. Ahmad, P.; Alam, M.; Jakubovics, N.; Schwendicke, F.; Asif, J. 100 years of the Journal of Dental Research: A bibliometric analysis. J. Dent. Res. 2019, 98, 1425-1436. [CrossRef] [PubMed]

75. Van Eck, N.J.; Waltman, L. Software survey: VOSviewer, a computer program for bibliometric mapping. Scientometrics 2010, 84, 523-538. [CrossRef] [PubMed]

76. Belli, S.; Baltà, J. Stocktaking scientific publication on bi-regional collaboration between Europe 28 and Latin America and the Caribbean. Scientometrics 2019, 121, 1447-1480. [CrossRef]

77. Belli, S.; Mugnaini, R.; Baltà, J.; Abadal, E. Coronavirus mapping in scientific publications: When science advances rapidly and collectively, is access to this knowledge open to society? Scientometrics 2020, 124, 2661-2685. [CrossRef]

78. Arshad, A.I.; Ahmad, P.; Karobari, M.I.; Asif, J.A.; Alam, M.K.; Mahmood, Z.; Abd Rahman, N.; Mamat, N.; Kamal, M.A. Antibiotics: A bibliometric analysis of top 100 classics. Antibiotics 2020, 9, 219. [CrossRef]

79. Ahmad, P.; Arshad, A.I.; Della Bella, E.; Khurshid, Z.; Stoddart, M. Systemic Manifestations of the Periodontal Disease: A Bibliometric Review. Molecules 2020, 25, 4508. [CrossRef]

80. Ahmad, P.; Della Bella, E.; Stoddart, M.J. Applications of Bone Morphogenetic Proteins in Dentistry: A Bibliometric Analysis. BioMed. Res. Int. 2020, 2020. [CrossRef] 